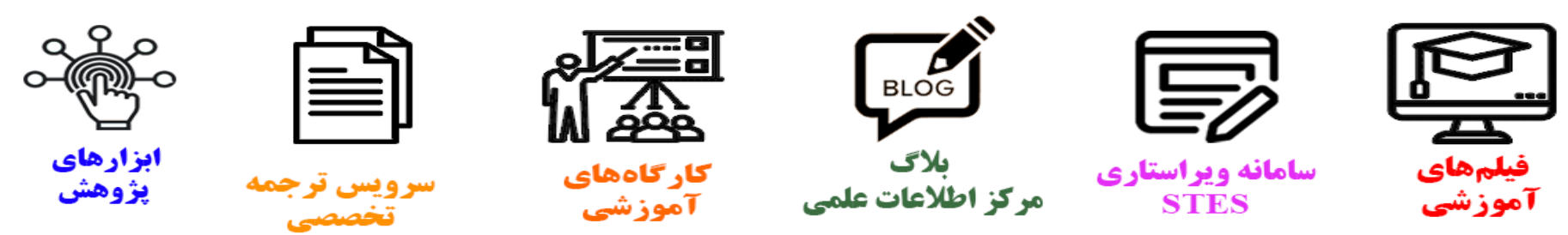

\title{
(c)
}

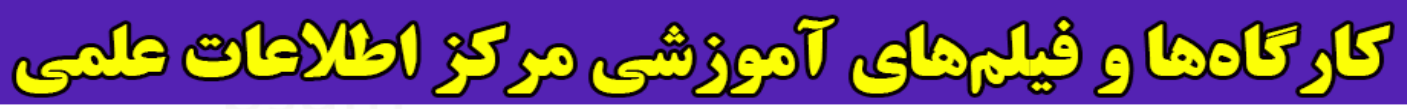
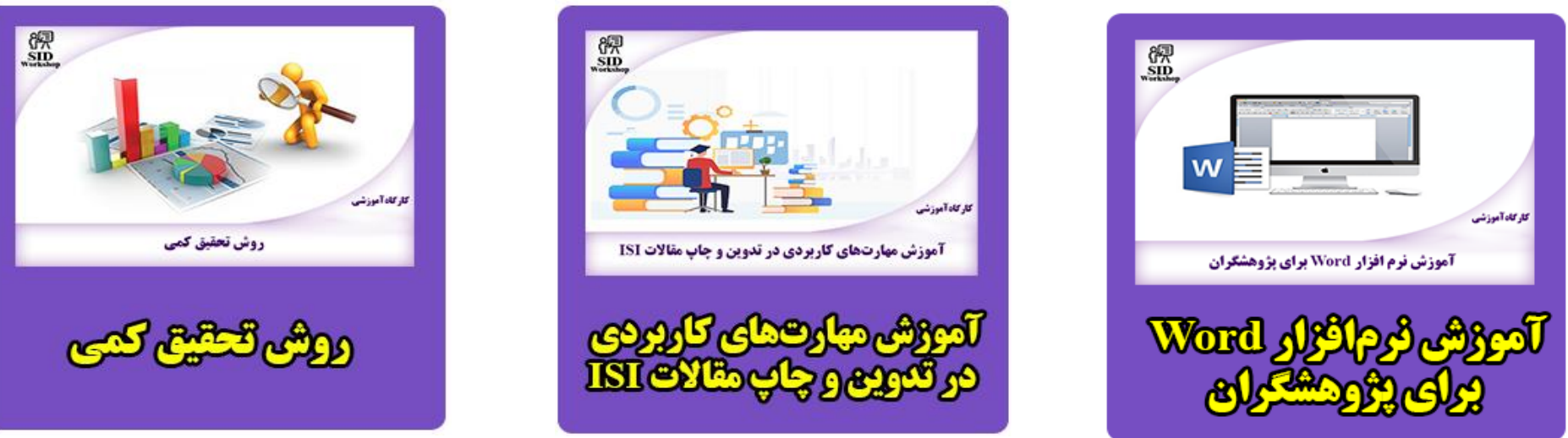


\title{
International Journal of Engineering
}

\section{Influence of Nano-silica and Polypropylene Fibers on Bond Strength of Reinforcement and Structural Lightweight Concrete}

\author{
S. H. Hashemi*a, I. MirzaeiMoghadam ${ }^{b}$ \\ aDepartment of Civil Engineering, Arak University, Arak, Iran \\ ${ }^{b}$ Department of Civil Engineering, Arak Branch, Islamic Azad University, Arak, Iran
}

\section{$P A P E R \quad I N F O$}

Paper history:

Received 19 June 2013

Accepted in revised form 22 August 2013

\section{Keywords:}

Taguchi Method

Polypropylene Fibers

Nano-silica

Bond Strength

Optimum Mix Design

\section{$A B S T R$ R A C T}

In this study, first by survey the parameters affecting the compressive strength, such as water to cement ratio, cementgrade, silica fume to cement percentage, and the various ratios of lightweight aggregate LECA to total aggregate. Taguchi method is used to examin optimization of the obtained 9 mix designs. Since lightweight concrete is brittle like normal concrete, to resolve this problem polypropylene fibers by $0.56 \%$ and $1 \%$ ratios of concrete volume was used. Moreover, to improve the mechanical properties and to study the effect of nano-silicain lightweight concrete and its effect on the adhesion between concrete and reinforcement in the mixes containing fibers, $1.5 \%$ and $3 \%$ nano-silica was added. Finally, the test result of specimens at ages 28 and 90 days resulted in the best mix to get highest bond strength between lightweight concrete and reinforcement, and it was found that adding fibers and nano-silica have great effect to improve the bond strength between lightweight concrete and reinforcement.

\section{INTRODUCTION}

Structural concrete with lightweight aggregates has been used in many applications since 1960s. Lightening the building has many advantages since much research has been done about it. For example, Kayali et al. [1] in a study in 2003 by adding polypropylene fibers at $0.56 \%$ and $1 \%$ by the volume of concrete, concluded that the addition of $0.56 \%$ polypropylene fibers can cause $90 \%$ increase in indirect tensile strength of high strength lightweight concrete containing fly ash, but the fibers did not have sizable effect on compressive strength and modulus of elasticity. In our country, Iran, because of the risky position in terms of seismic, and of course existence of plenty of industrial and mineral clinker resources, a lot of research has been conducted on the concrete with lightweight aggregate. Mostofinejad and Farahbod in a research on examining the mechanical properties of concrete containing pumice and leca and silica fume, concluded that the use of $10 \%$ silica fume in lightweight concrete with both lightweight aggregate, although improved mechanical properties compared to

*Corresponding Author Email: h-hashemi@araku.ac.ir (S. H. Hashemi) normal lightweight concrete, but this effect was not significant enough; so that the compressive strength and modulus of elasticity increased 5 to $10 \%$ [2]. To ensure an optimum mix there are several various statistical methods, which Taguchi method matched with the laboratory results more than other methods. Afshin et al. [3] in a study on parameters affecting the compressive strength and weight of structural light weight concrete, concluded that mixture designs suggested by the Taguchi method has good match with the results of experiments, and Taguchi method can be used as a method for predicting the properties of lightweight aggregate structural concrete. In 2007, in Turkey, Tanyildizi [4] searched on fuzzy logic model to predict the bond strength of reinforcement and high strength lightweight concrete was cured at different conditions, it was concluded that replacement of $10 \%$ of cement with silica fume and also curing samples in water had the best result with the highest compressive strength and bond strength at all ages. With the development of technology and production in nano scale materials, nano-silica was used as a concrete additive. According to Ramezaniyanpour et al. [5], nano-silica increased the compressive strength of concrete at early ages and speed of gain strength at an early age in the sample containing 
nano-silica is more than sample containing silica fume but at the age of 28 days the difference between the compressive strength of silica fume and nano-silica with same replacement of sample was very small. Qing et al. [6] examined the effects of adding nano-silica and micro-silica on properties of hardened cement paste by measuring the compressive strength and connective strength by XRD and SEM analysis; their results indicated that the effects of nano-silica and silica fume were different from each other. Nano-silica is more concentrated cement paste and accelerates cement hydration process. Compressive strength and connective strength of cement paste aggregate interface in cement replaced by nano-silica added to $3 \%$ was higher at early ages against concrete containing 3\% micro-silica, at the same age, but with the passage of time, at the age of 60 days the difference is reduced. Since the industrial clinker Leca's shape is a round and circular, there is probable lean adhesion with reinforcement. In this study, we are looking for a way to examine this hypothesis and seeking the combined effects of polypropylene fibers and nano-silica on bond strength between reinforcement and structural lightweight concrete containing industrial clinker Leca and its relationship with compressive strength.

\section{MATERIALS USED AND THEIR PROPERTIES}

In this study, to make concrete specimens, we used the following materials: Delijan Portland cement type $\Pi$ with $3.1 \mathrm{~g} / \mathrm{cm}^{3}$ grain density, silica fume made in Azna
Fro Aliyazh industry with $2 \mathrm{~g} / \mathrm{cm}^{3}$ grain density the third generation super plasticizer M63 based on sulfonate melamine with $1.098 \mathrm{~kg} / \mathrm{l}$ density, colloidal nano-silica solution in water with $50 \%$ concenteration made in Wandshimi factory with details in Table 1 and SEM micrograph in Figure 1, $12 \mathrm{~mm}$ polypropylene fibers with properties listed in Table 2, and washed out natural sand passing through $4.75 \mathrm{~mm}$ sieve with 77 sand equivalent and moisture content of $6.17 \%$ and a specific gravity of $2.704 \mathrm{~g} / \mathrm{cm}^{3}$. Used Leca was the structural type products of Saveh Leca factory and since water absorption of aggregate in concrete is stopped about after $30 \mathrm{~min}$, water absorption in half-hour is used in the calculation mix design. Physical properties of Leca aggregates are presented in Table 3. All tests were performed in concrete technology part of Arak technical and soil mechanics laboratory.

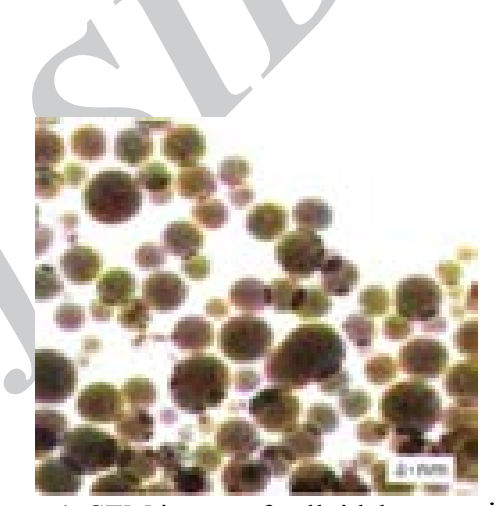

Figure 1. SEM image of colloidal nano-silica

TABLE 1. Details of Nano silica

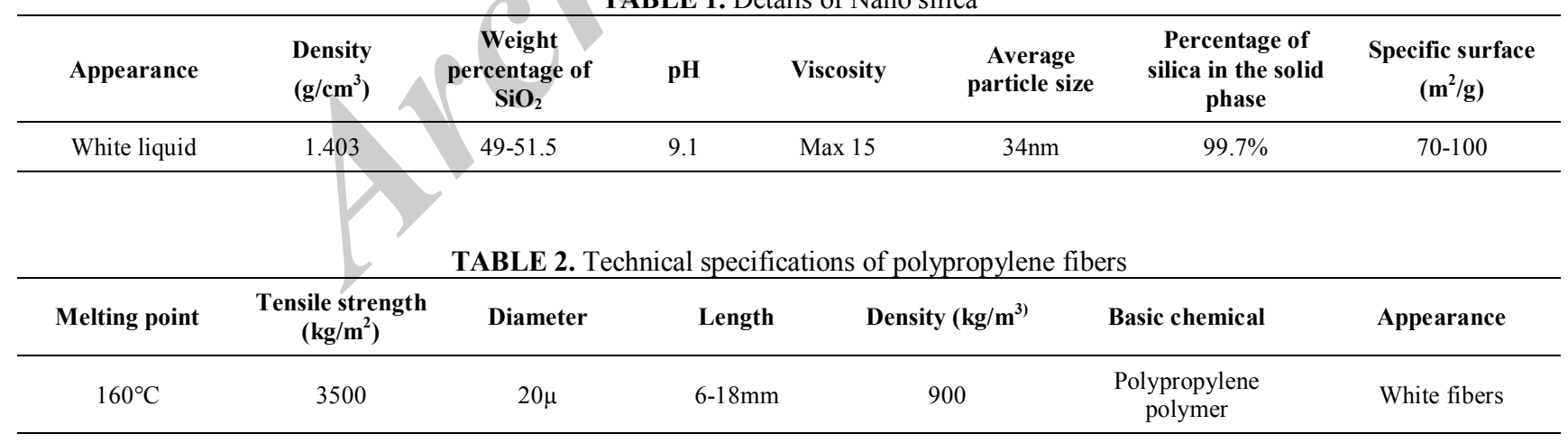

TABLE 3. Physical characteristics of Leca lightweight aggregate

\begin{tabular}{ccccc}
\hline $\begin{array}{c}\text { 24-hour water } \\
\text { absorption percentage }\end{array}$ & $\begin{array}{c}\text { Half-hour water absorption } \\
\text { percentage }\end{array}$ & Density (gr/cm $\mathbf{c}^{3}$ & Grain size (mm) & Sieve No. \\
\hline \multirow{2}{*}{12.52} & & 0.74 & $9.5-12.5$ & $3 / 8$ \\
& 9.5 & 0.75 & $4.75-9.5$ & 4 \\
\hline
\end{tabular}




\section{DETERMINATION OF MIX DESIGN RATIOS}

Determined method of mix design is the volumetric method according to ACI 213R-03. In this method, the volume of fresh concrete obtained considered to be equal by summing the absolute volume of cementitious materials, aggregates, efficient water, trapped air and other additives.

Mix ratios determined using this method are required to determine the amount of water absorbed and density of aggregates with different grain size [7]. For an optimum mix, first the most important variables affecting the compressive strength of concrete will be considered including: 1 -ratio of water to cementitious materials, 2-grade of cement, 3-percentage of microsilica to cement and 4-Leca ratio to total aggregates.

According to studies conducted for variable amounts of water to cementitious materials ratio are $0.3,0.35$ and 0.4 and also for variable cement grade numbers are 350 , 400 and $450 \mathrm{~kg} / \mathrm{m}^{3}$ and for variable percentage of micro-silica to cement numbers are $0 \%, 5 \%$ and $10 \%$ that replace with part of used cement and finally for lightening the concrete samples use of Leca to total aggregate volume ratio by amounts $0.5,0.65$ and 0.85 are used. These variables are introduced to Qualitek-4 software, which is based on the Taguchi statistical method. The amount of super plasticizer will be added between $2-4 \%$ by weight of cementitious materials to maintain a constant consistency in all designs.

Based on the Taguchi method, the software offers a 9 mix as listed in Table 4 . Three cubic $10 \times 10 \times 10 \mathrm{~cm}$ samples were made from all of offered mix design and at the age of 7 days compressive strength were measured. By entering the experimental data as shown in Table 5and performing ANOVA analysis of variance, the software suggested optimum design to get the highest compressive strength as shown in Table 6 .

Three cubic $10 \times 10 \times 10 \mathrm{~cm}$ samples were made from mix proposed by the software for maximum strength (T10) in laboratory and at the age of 7 days the average compressive strength was $302 \mathrm{~kg} / \mathrm{cm}^{3}$ and the average weight was $1761.5 \mathrm{~g}$. There was a difference about $5.6 \%$ from the suggested mix design and also difference of $17.14 \%$ from the average weight.

Taguchi method also offers a mix design to have the lowest weight at which constructed laboratory mix sample had a compressive strength of $185 \mathrm{~kg} / \mathrm{cm}^{3}$ and weight at 7 days $1512 \mathrm{~g}$ which had difference of $0.79 \%$ with suggested weight means of $1499.99 \mathrm{~g}$. Also the smple had a strength to weight ratio of $12.23 \%$; that was due to high strength to weight ratio of T10 mix design. The optimum mix design was selected for continuation of the study. Polypropylene fibers were added to the sample at 0.56 and $1 \%$ volume of concrete and similar design was made with addition of 1.5 and $3 \%$ Nano silica that replaced with cement, and the prepared examined.

\section{EXPERIMENTAL PROGRAM}

4. 1. Concrete Mixing Method In order to match the making conditions and increasing the accuracy of test results, consistent mixing method was used for all mixing design schemes. For making concrete specimens firstly cement and micro-silica was mixed well, then added to Leca aggregates which was mixed with sand in mixer for $30 \mathrm{sec}$. One min after mixing polypropylene fibers are added to the mixture of aggregate and cementitious materials in two stages then mixing operation continued for $1.5 \mathrm{~min}$. At the end, water and super plasticizer was mixed well then half of it was first added to the total material and 2 min later the other half of it with nano-silica was added and mixing operation continued for $2 \mathrm{~min}$ in order to ensure the complete distribution of fibers in concrete.

4. 2. Curing of Concrete Specimens In order to cure concrete, specimens covered in plastic in mold for $24 \mathrm{~h}$ to keep moisture and then placed in pond water at $19-23^{\circ}$ C. Samples at the age of 28 days were removed from curing pond and kept in laboratory environment . In this study, cube mold $15 \times 15 \times 15 \mathrm{~cm}$ and rebar Reinforcement with a diameter of $16 \mathrm{~mm}$ was used. Figure 2 shows details of preparation and placement of rebar in the middle of cubs.

4. 3. Experiments Procedure By determination the basic initial mix, 7 batch mix designs were tested which values of their components are presented in Table 7 . Because of reduction of workability of concrete by addition of more polypropylene fibers, so more super plasticizer were used. Polypropylene fibers was added to $0.56 \%$ and $1 \%$ of the concrete volume, according to research conducted by Kayali et al. [1] effect of adding fibers on structural lightweight concrete properties given in Table 7 was examined; which was named P0.56 and P1. Meanwhile, LWplain indicates lightweight concrete samples named N1.5 and N3 which show the presence of 1.5 and $3 \%$ of nano-silicate replaced cement. In order to examine the effect of nano silicates added to each sample containing mix fibers, 3 samples of mixed design were preperd. The reinforced bars with diameter of $16 \mathrm{~mm}$ was placed in the middle of cubical block of concret with size of $15 \times 15 \mathrm{~cm}$ (Figure 2). After 28 days of curing in water, samples were removed from the pond and placed in laboratory environment. Samples by standard bar puller RILEM/CEB/FIP standard were tested (Figure 3), shear stress between reinforcement and concrete was calculated at ages 28 and 90 days according to the relation given below: 
$\tau=\frac{P}{\pi d l}\left(\frac{\mathrm{kg}}{\mathrm{cm}^{2}}\right)$

where, $P$ is stretching force $(\mathrm{kg}), d$ shows rebar diameter $(\mathrm{cm})$, and $l$ is the fixity bar length $(\mathrm{cm})$. For investigation relationship between bond strength and compressive strength of each mix design, cubic $10 \times 10 \times 10 \mathrm{~cm}, 3$ samples that were processed in a similar situation were made.

TABLE 4. Initial value of mixing design using the Taguchi method $\left(\mathrm{kg} / \mathrm{m}^{3}\right)$

\begin{tabular}{|c|c|c|c|c|c|c|c|c|}
\hline Sand & 8 Leca & 4 Leca & 3/8 Leca & Super plasticizer & Water & Silica fume & Cement & Mix design No. \\
\hline 1048.9 & 120.4 & 151.28 & 45.92 & 8.75 & 105 & 0 & 350 & $\mathrm{~T} 1$ \\
\hline 734.22 & 156.52 & 196.66 & 59.7 & 10 & 120 & 20 & 380 & $\mathrm{~T} 2$ \\
\hline 314.67 & 204.68 & 257.1 & 78.1 & 11.25 & 135 & 45 & 405 & T3 \\
\hline 314.67 & 204.68 & 257.1 & 78.1 & 8.75 & 122.5 & 17.5 & 332.5 & $\mathrm{~T} 4$ \\
\hline 1048.9 & 120.4 & 151.28 & 45.92 & 10 & 140 & 40 & 360 & T5 \\
\hline 734.22 & 156.52 & 196.66 & 59.7 & 11.25 & 157.5 & 0 & 450 & T6 \\
\hline 734.22 & 156.52 & 196.66 & 59.7 & 8.75 & 140 & 35 & 315 & $\mathrm{~T} 7$ \\
\hline 314.67 & 204.68 & 257.1 & 78.1 & 10 & 160 & 0 & 400 & $\mathrm{~T} 8$ \\
\hline 1048.9 & 120.4 & 151.28 & 45.92 & 11.25 & 180 & 22.5 & 427.5 & T9 \\
\hline
\end{tabular}

TABLE 5. Results of making initial samples

\begin{tabular}{ccc}
\hline Compressive strength average $\mathbf{( k g / \mathbf { c m } ^ { 2 } )}$ & Weight average $\mathbf{( g r})$ & Mix design No. \\
\hline 161.13 & 1852.66 & $\mathrm{~T} 1$ \\
310.96 & 1813 & $\mathrm{~T} 2$ \\
272 & 1594 & $\mathrm{~T} 3$ \\
215.3 & 1544 & $\mathrm{~T} 4$ \\
354 & 1973 & $\mathrm{~T} 5$ \\
272.33 & 1855 & $\mathrm{~T} 6$ \\
269 & 1786 & $\mathrm{~T} 7$ \\
182.66 & 1617 & $\mathrm{~T} 8$ \\
322.9 & 1958 & $\mathrm{~T} 9$ \\
\hline
\end{tabular}

TABLE 6. Suggested mix design software $\left(\mathrm{kg} / \mathrm{m}^{3}\right)$ for highest compressive strength

\begin{tabular}{cccccccccc}
\hline Expected strength $\left(\mathbf{k g} / \mathbf{c m}^{2}\right)$ & Sand & $\mathbf{8}$ Leca & 4 Leca & 3/8 Leca & Super plasticizer & Water & Silica fume & Cement & Mix design No. \\
\hline 320 & 734.22 & 156.52 & 196.66 & 59.7 & 10 & 140 & 40 & 360 & $\mathrm{~T} 10$ \\
\hline
\end{tabular}
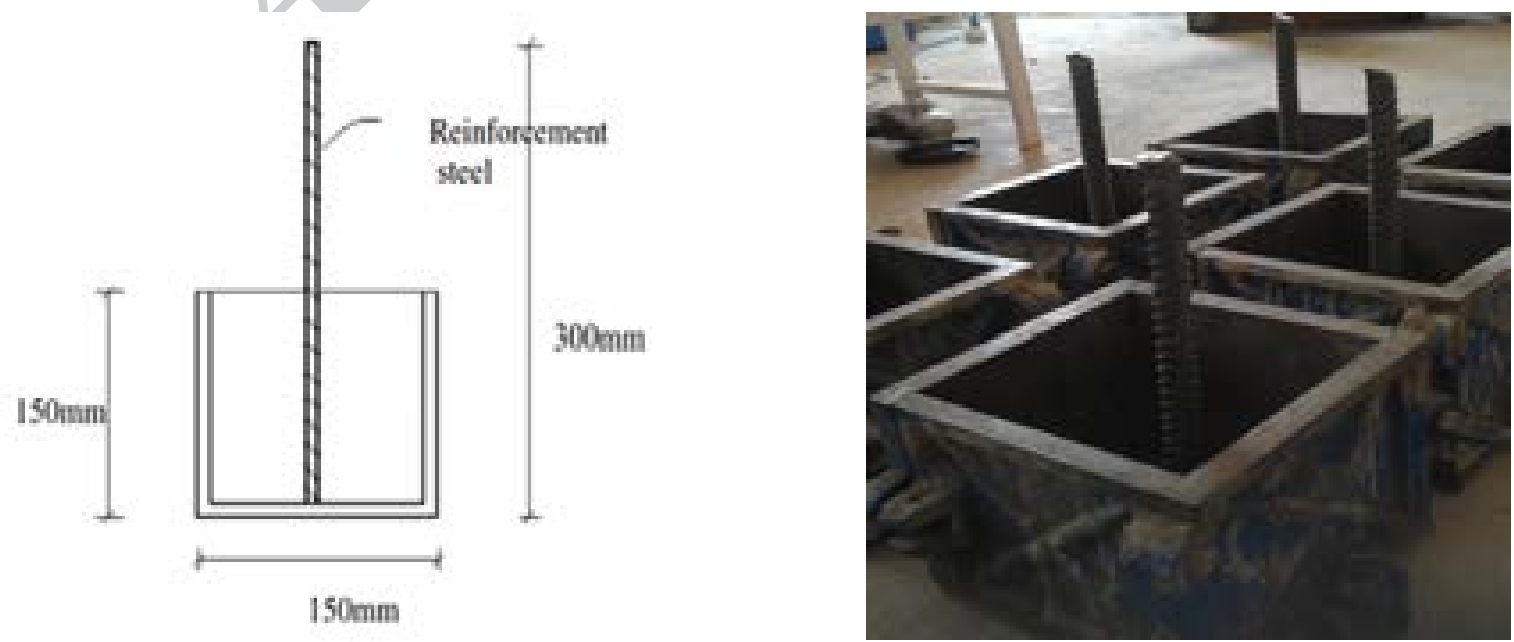

Figure 2. Details of reinforcement and mold 
TABLE 7. Values of each components of each mix design $\left(\mathrm{kg} / \mathrm{m}^{3}\right)$

\begin{tabular}{|c|c|c|c|c|c|c|c|c|c|c|}
\hline $\begin{array}{c}\text { Polypropylene } \\
\text { fibers } \\
\end{array}$ & Sand & $\begin{array}{c}8 \\
\text { Leca } \\
\end{array}$ & $\begin{array}{c}4 \\
\text { Leca } \\
\end{array}$ & $\begin{array}{c}3 / 8 \\
\text { Leca } \\
\end{array}$ & $\begin{array}{c}\text { Super } \\
\text { plasticizer }\end{array}$ & Water & $\begin{array}{l}\text { Nano } \\
\text { silica }\end{array}$ & $\begin{array}{l}\text { Silica } \\
\text { fume }\end{array}$ & Cement & $\begin{array}{c}\text { Concrete } \\
\text { type }\end{array}$ \\
\hline- & 734.22 & 156.52 & 196.66 & 59.7 & 10 & 140 & - & 40 & 360 & LWplain \\
\hline 5 & 734.22 & 156.52 & 196.66 & 59.7 & 12 & 140 & - & 40 & 360 & LWP0.56 \\
\hline 9 & 734.22 & 156.52 & 196.66 & 59.7 & 16 & 140 & - & 40 & 360 & LWP1 \\
\hline 5 & 734.22 & 156.52 & 196.66 & 59.7 & 12 & 140 & 5.4 & 40 & 354.6 & LWP0.56N1.5 \\
\hline 5 & 734.22 & 156.52 & 196.66 & 59.7 & 12 & 140 & 10.8 & 40 & 349.2 & LWP0.56N3 \\
\hline 9 & 734.22 & 156.52 & 196.66 & 59.7 & 16 & 140 & 5.4 & 40 & 354.6 & LWP1N1.5 \\
\hline 9 & 734.22 & 156.52 & 196.66 & 59.7 & 16 & 140 & 10.8 & 40 & 349.2 & LWP1N3 \\
\hline
\end{tabular}

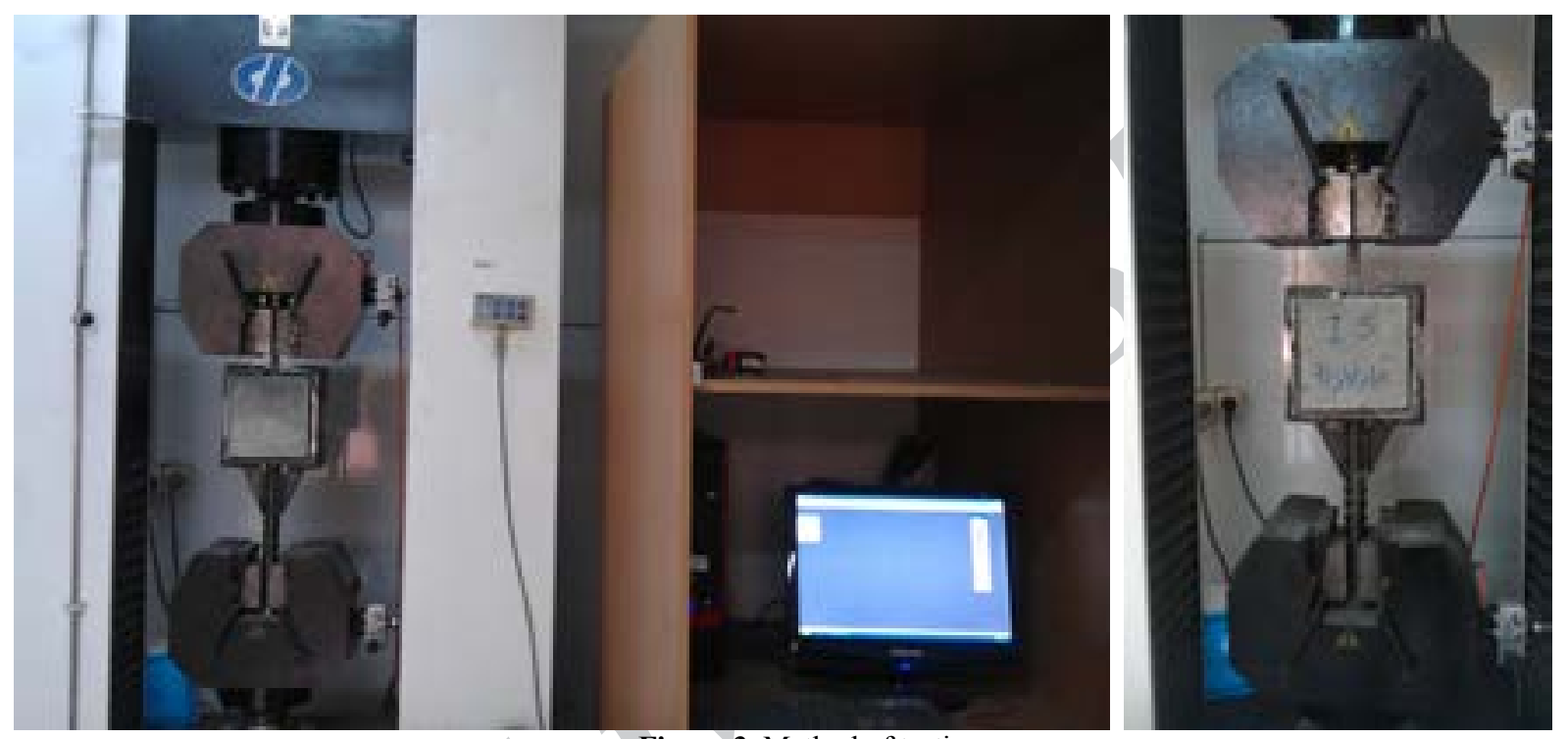

Figure 3. Method of testing

\section{EXPERIMENTAL RESULTS AND ANALYSIS}

For each 7 mix design tested, the compressive strength at ages 7, 28 and 90 days and bond strength between concrete and reinforcement were measured at ages 28 and 90 days. Each test result is the average of the 3 samples obtained at any age.

5. 1. Bond Strength Testing of Rebar and Lightweight Concrete This experiment shows that stop of pulling out of reinforcement within the concrete occurs in two different modes: 1. pulling out reinforcement without breaking concrete sample. 2 . pulling-out reinforcement with fracture of concrete sample. Figure 4 shows the difference of these modes. The first mode of failure occurred in all six designs containing fibers. The second mode was observed just in the control sample without fiber and nano-silica. The results of the tests for 28 and 90 days are presented in Figure 5. As it is demonstrated in Figure 5, at the age of 28 days, by addition of polypropylene fibers the bond strength of concrete and reinforcement in LWP1 and
LWP0.56 samples incomparison with LWpalin were increased 41 and 44\%, respectively. Addition of nanosilicate to samples containing $1 \%$ fibers showed high performance and the strength of LWP1-N1.5 in compare to control sample has increase by $67 \%$. The samples containing $1 \%$ fibers had the highest performance and the strength of LWP1-N1.5 in compare to LWpalin sample has increased by $90 \%$. Because of the absence of nano-silica in control sample the increase of its strength was not considerable at the age of 28-day. Another point of this graph that obtained is adding polypropylene fibers is more effective in achieving high bond strength between concrete and reinforcement in comparison to nano-silica because fibers affect structure of mortar and aggregates. Because of the fiber acts as bridge binder between two pieces aggregates that assisted the tensile strength of concrete matrix to increase. However, addition of nano-silicate increased the compressive strength of concrete. The nano-silica with dense C-S-H gel formation enhanced the strength of transition surface zone so improved the bond strength of samples containing $1 \%$ fibers and nano-silica in comparison with 
samples without nano-silica but this subject in samples containing $0.56 \%$ fibers did not observed. The compressive strength test results of this study were as follows.

\section{2. Compressive Strength Tests The most} important mechanical property of concrete is compressive strength because of its direct relation with many of the properties of concrete. In many practical synthetic applications the goal of using fibers in concrete is not increase its strength. Rather, the goal is maintaining compressive strength and enhancing positive benefits such as controlling cracks the tensile strength, flexural strength, shrinkage. The compressive strength test results are shown in Figure 6. As can be seen in Figure 6, samples containing 1\% polypropylene fibers resist adhesion between reinforcement and concrete and had the highest compressive strength and lower weight than other designs even than concrete control samples. The increase in fibers values results decreased in compressive strength.

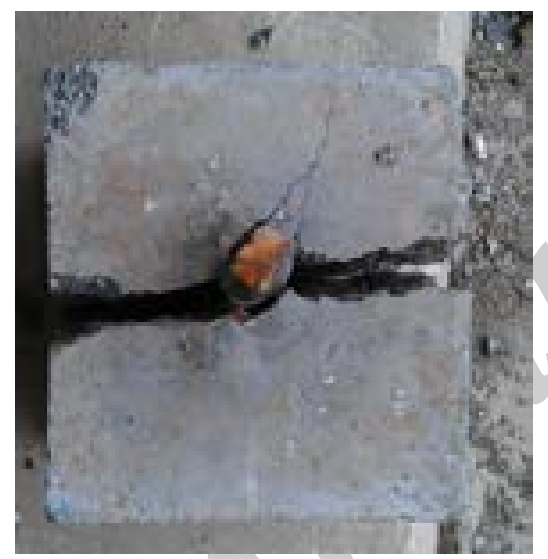

(a)

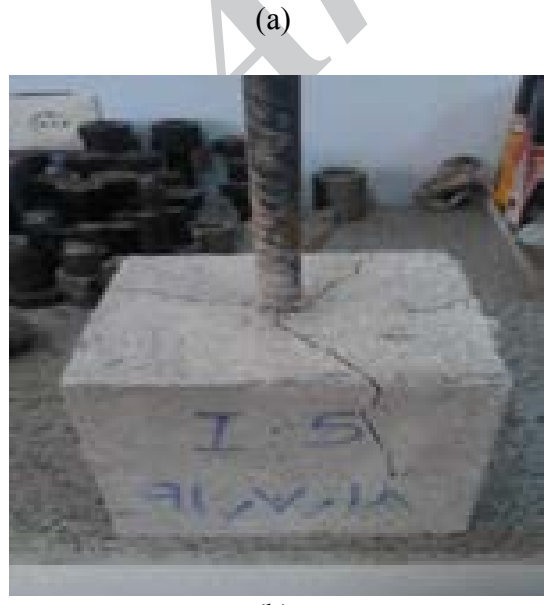

(b)

Figure 4. Failure modes of concrete: a.contains no fibers and nano-silica, b. containing both fibers and nano-silica
Similar results are observed in Esmaili and Ghahari [8] research on concrete sleeper fiber reinforced polypropylene. But adding nano-silica causes to decrease pozzolanic activities and decreases the orientation of $\mathrm{CH}$ crystals, reduces the size of $\mathrm{CH}$ crystals at the interface and improves the interface structure [6]. Also in a study reported that the compressive strength of SCC mixes can be increased while the SCC design is consisted of both microsilica as well as nanosilica [9]. Graphs of Figure 7 shows the relationship between compressive strength and bond strength.

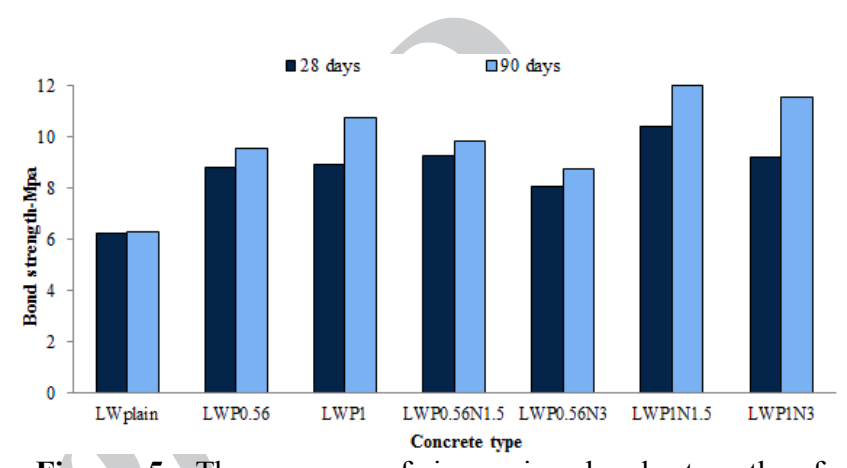

Figure 5. The process of increasing bond strength of reinforcement and lightweight concrete

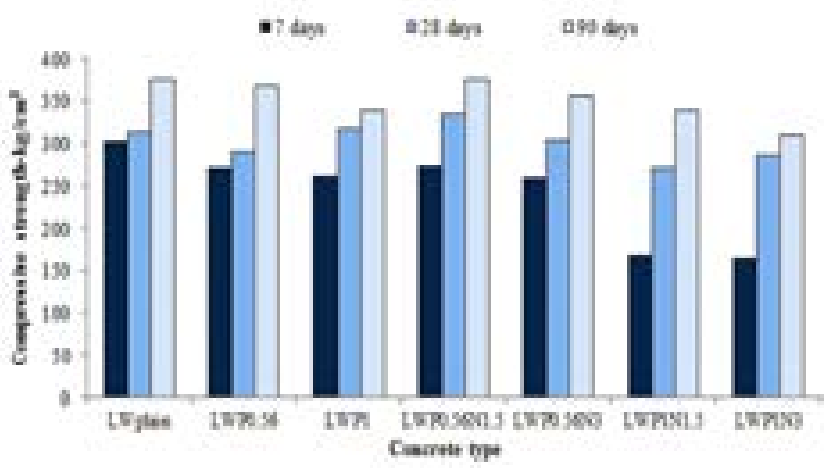

Figure 6. Results of compressive strength tests at ages 7, 28 and 90 days

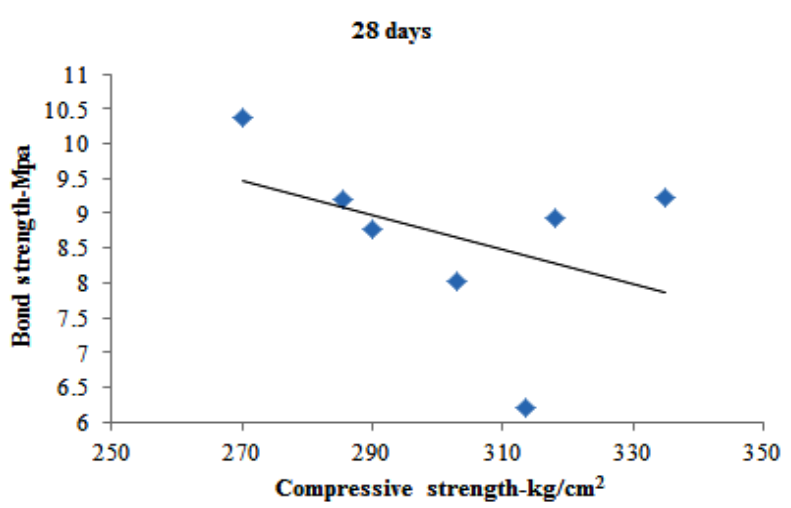




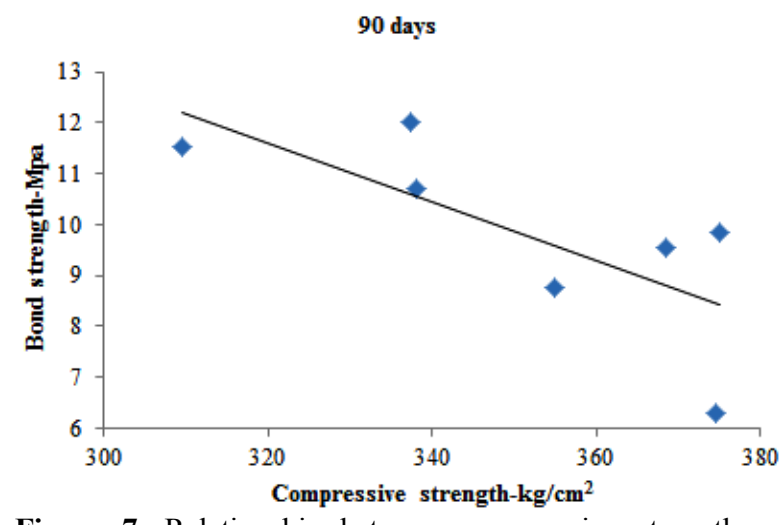

Figure 7. Relationship between compressive strength and bond strength at ages of 28 and 90 days

As specified, compressive strength with adhesion strength are in inverse relation. Bond strength decreased with increasing compressive strength of concrete and vice versa. This is because of dual behavior of fibers in pushing and pulling. Research shows that adding fiber to reinforced concrete due to reinforcing in three directions can be effective in increasing ductility and resistance to a variety of small and large cracks. After occurrence of cracks, fibers act such as bridge and hold initial cracks near together and bear load [10]. By increasing in the amount of fibers in the concret sample, there is an increase in the likelihood that fibers placed near together and intertwined, caused the weakness of the concrete matrix at high pressure.

\section{CONCLUDING REMARKS}

According to results, summarized conclusions of this experimental study the most important results are as follows:

1. Taguchi statistical method is an appropriate and acceptable way for the design of structural lightweight concrete. It was found that replacement of $10 \%$ of the cement by micro-silica in absence of nano-silica had the greatest impact on increasing the strength of lightweight concrete at age of 7 days.

2. The use of polypropylene fibers decreased strength flow ability and density of lightweight concrete samples but adding nano-silica of $1.5 \%$ weight of cement, recover resistance loss and increases compressive strength especially at the age of 28 days .

3. Adding nano-silica strengthens transition zone between the surface and adding polypropylene fibers causes change of the failure mode and traction detachment of the reinforcement in concrete becomes ductile from the brittle mode.
4. Adding polypropylene fibers by $1 \%$ of concrete volumes increased $70 \%$ bond strength of concrete and the reinforcement. While adding strengthens and polypropylene fibers simultaneously can make an increase up to $90 \%$ in bond strength of light weight concrete and reinforcement.

5. For getting the maximum bond strength between reinforcement and lightweight concrete containing Leca aggregate, the best ratio is $1.5 \%$ replacement cement weight with nano-silica and adding polypropylene fibers up to the $1 \%$ of concrete volume.

6. Recommended concrete samples are kept for long time in aggressive environment then the experiment will once again down to better understand the impact of addition of nano-silica.

\section{ACKNOWLEDGMENT}

The authors appreciate of the unwavering efforts of the management and staffs of the Arak Parent Company Technical and Soil Mechanics Laboratory to provide the possibility of various testing.

\section{REFERENCES}

1. Kayali, O., Haque, M. and Zhu, B., "Some characteristics of high strength fiber reinforced lightweight aggregate concrete", Cement and Concrete Composites, Vol. 25, No. 2, (2003), 207213.

2. Mostofinejad, D. and Farahbod, F., "Investigation on mechanical properties of structural lightweight concrete using existing materials in iran and micro silica", in in6th International Conference on Civil Engineering. University of Technology of Isfahan. (2003)

3. Afshin, H., Babalou, A. A. and Ejlali, A., "Finding optimum mix design of structural lightweight aggregate concretes using the taguchi method ", in 7th International Congress on Civil Engineering, Tarbiat Modares University of Tehran. (2006)

4. Tanyildizi, H., "Fuzzy logic model for the prediction of bond strength of high-strength lightweight concrete", Advances in Engineering Software, Vol. 40, No. 3, (2009), 161-169.

5. Ramezaniyanpour, A. A., Moravej jahromi, S. M. and Mehdikhani, M., "Compare the effects of nano silica and silicafumeon themicrostructureand durabilityofconcrete", in 1st International Conference onConcrete Technology, National Center forRetrofitting, Tabriz. (2009)

6. Qing, Y., Zenan, Z., Deyu, K. and Rongshen, C., "Influence of Nano- $\mathrm{SiO}_{2}$ addition on properties of hardened cement paste as compared with silica fume", Construction and Building Materials, Vol.21, No. 3, (2007), 539-545.

7. ACI 213R, "Guide for structural lightweight aggregate concrete", in ACI Journal Proceedings, ACI. Vol. 64, (1967).

8. Esmaili, M. and Ghahari, S. A., "Laboratory study on the effect of poly-propylene fiber reinforced concrete for application in sleeper", The Modares Journal of Civil Engineering, Vol. 12, (2012), 91-101. 
9. Maghsoudi, A. and Arabpour, D. F., "Application of nanotechnology in self-compacting concrete design",

International Journal of Engineering, Vol. 22, (2009), 229244.
10. Madandoust, R., Motaghitalab, V., Mousavi, S. Y. and EbrahimnejadShalmani, M., "Mechanicalproperties ofnylonfibersreinforced concrete (NFRC)", in 8thInternational Congress on Civil Engineering. Shiraz University. (2009)

\section{Influence of Nano-silica and Polypropylene Fibers on Bond Strength of RESEARCH Reinforcement and Structural Lightweight Concrete

S. H. Hashemia, I. MirzaeiMoghadam ${ }^{b}$

aDepartment of Civil Engineering, Arak University, Arak, Iran

${ }^{b}$ Department of Civil Engineering, Arak Branch, Islamic Azad University, Arak, Iran

PAPER INFO

\section{Paper history:}

Received 19 June 2013

Accepted in revised form 22 August 2013

\section{Keywords:}

Taguchi Method

Polypropylene Fibers

Nano-silica

Bond Strength

Optimum Mix Design

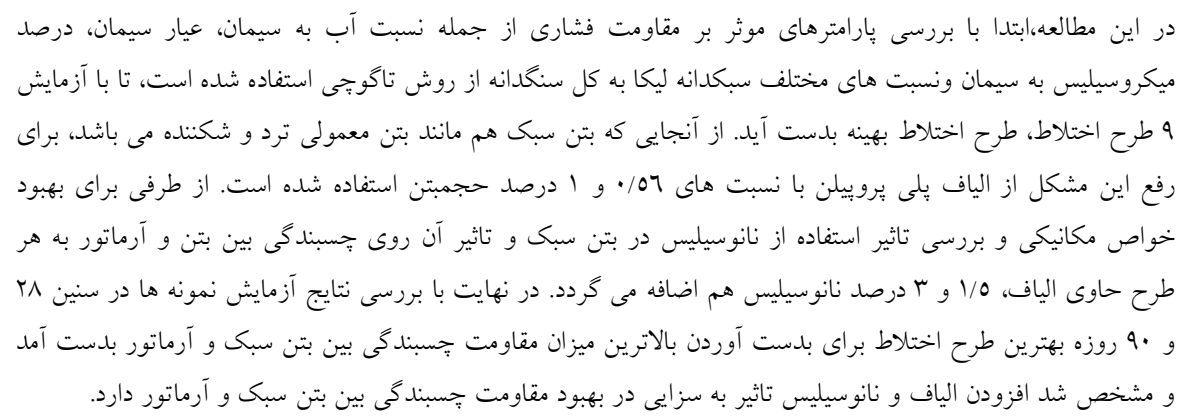

doi: $10.5829 /$ idosi.ije.2014.27.02b.10 


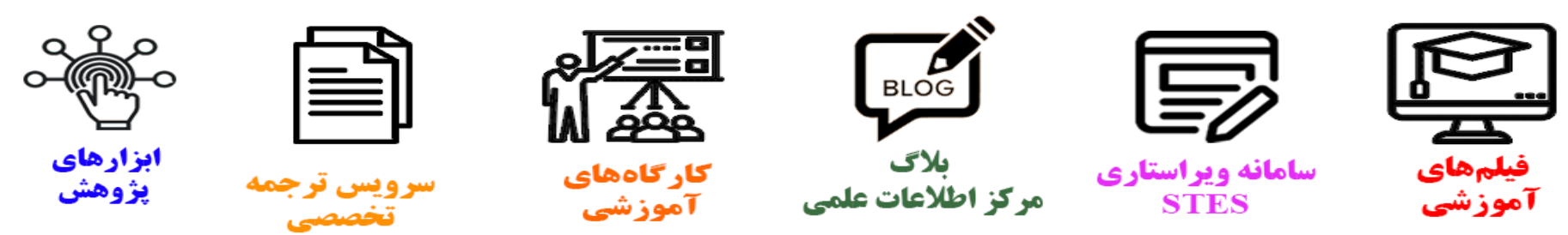

\section{(c)}

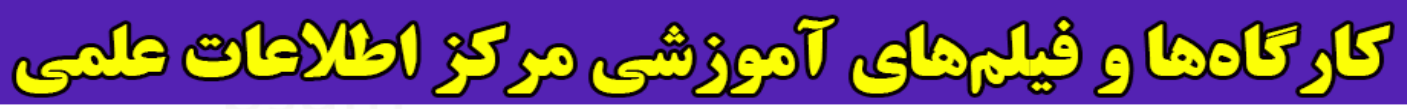
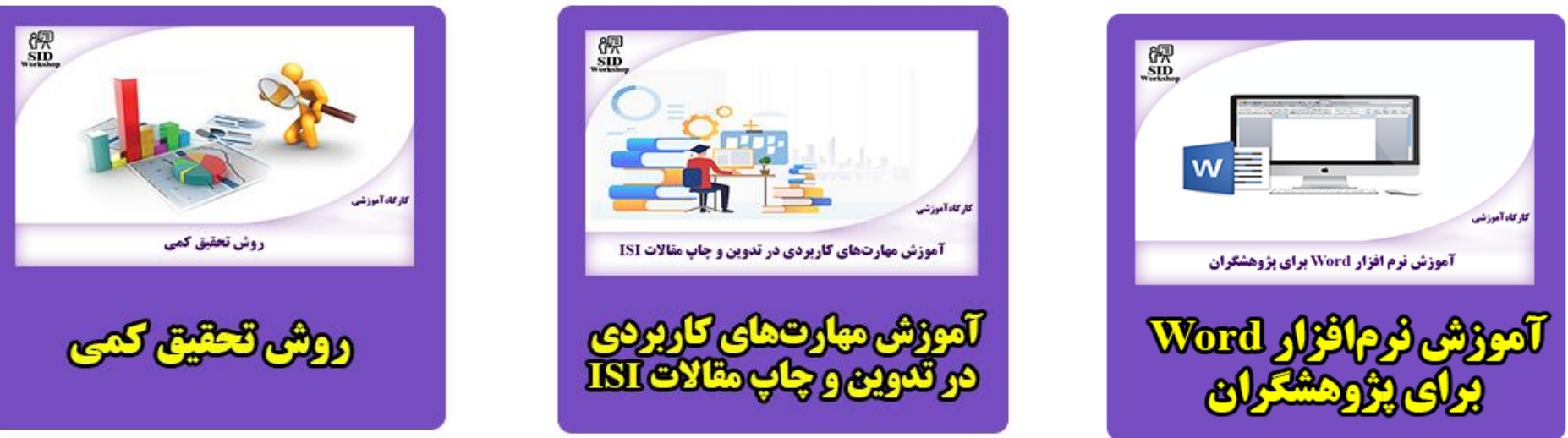